\title{
DÖDSSTRAFFEN I FINLAND UNDER ANDRA VÄRLDSKRIGET
}

\section{AV LAGSTIFTNINGSRÅD, JUR. DR. JUKKA LINDSTEDT}

This article is based on the author's dissertation on capital punishment in Finland during World War II, i.e. in effect the Finnish-Russian Winter War (from November 1939 to March 1940) and the Finnish-Russian Continuation War (from June 1941 to September 1944). Previous research has shown that civilian administrations generally adapt to special wartime requirements. Acknowledging that capital punishment can be seen as a barometer of wartime jurisdiction, the author sets out 1) to clarify the number of death sentences and executions, 2) to examine the legal proceedings observed, in particular regarding the rights of the accused, such as the independence of the courts, the presumption of innocence, and questions of defence and appeal, and 3) to assess the objectives of the death penalties and their implementation.

The death sentences amounted to 681, of which $85 \%$ were imposed by field courts martial and most of the rest by other military courts. Only 16 persons were sentenced to death by civilian general courts.

In all, 522 Soviet citizens and 157 Finnish citizens were sentenced to death. 443 of the former, and 85 of the latter were ultimately executed. Most of the Soviets had been found guilty of espionage. Other crimes leading to capital punishment were desertion, high and war treason, homicide, crimes committed by prisoners of war, and disobedience. The last execution in Finland was carried out on 15 September 1944.

The author concludes that peacetime legal ideals, on the whole, maintained their integrity quite well in the military courts and, more general$l y$, in wartime jurisdiction. However, the pressure to apply severe and expedient procedures according to military principles was obvious. The finding of previous studies that militarist administrative culture often gains a prevalent position in times of crises was confirmed. This was also reflected in Parliamentary debates on the question of capital punishment.

On the basis of the investigation it is difficult to discern any constructive effect of capital punishment, even in times of war. It generally seems to be an unreasonable sanction with respect to the nature of the offences, especially when assessed from a post-war perspective.

In 1949, capital punishment was abolished in peacetime in Finland, and in 1972, altogether. The author concludes that the possibility of error, which in times of crises is likely to increase, constitutes a most weighty argument against sentencing people to death. *

\footnotetext{
* Title in English: Capital Punishment in Finland during World War II. Original in Swedish.
} 
Under andra världskriget dömdes de flesta dödsstraffen i Finland ut av krigsdomstolar: fältkrigsrätter, ståndrätter och överkrigsdomstolen. Endast ett fåtal dömdes ut av allmänna domstolar.

Finland förde två krig mot Sovjetunionen, vinterkriget (november 1939-mars 1940) och fortsättningskriget (juni 1941-september 1944). Efter fortsättningskriget förde Finland dessutom det s.k. lappska kriget mot Tyskland. Under detta krig, som upphörde först våren 1945, dömdes inga finländare till döden.

\section{Utgångspunkterna för undersökningen}

Tidigare forskning har gett vid handen att också en del av civilförvaltningen under krig blir tvungen att anpassa sig till krigstida specialkrav, vilket innebär att de förvaltningsprinciper som gäller under fredstid eventuellt får ge vika. Domstolarna representerar en förvaltningsgren där det även under krig är särdeles angeläget att de rättsstatliga principerna iakttas. Under andra världskriget skulle principerna i fråga följas också vid de finska krigsdomstolarna, som ju utgjorde oberoende domstolar.

Dödsstraffen är till följd av sin stränga och oåterkalleliga natur ett utmärkt forskningsobjekt, när man vill bedöma hur domstolar och andra myndigheter som behandlade brottmål skötte sina åligganden under krigstiden. Man kan säga att domstolarnas och de övriga myndigheternas dödsstraffdomar bör uppfylla de allra högsta kvalitetskrav.

Artikeln grundar sig på min doktorsavhandling om utdömda dödsstraff i Finland under andra världskriget. ${ }^{1}$ I avhandlingen har jag granskat faktorer som tryggar den åtalades (misstänktes) rättsskydd vid förfarandet, såsom domstolens oberoende, oskyldighetspresumtionen samt försvars- och besvärsmöjligheterna. Jag har utgått från den rättsskyddsuppfattning som var förhärskande vid den undersökta tidpunkten, således inte från dagens uppfattningar.

Dödsstraffet har diskuterats redan länge. I debatten har argumenten för och mot dödsstraff varit tämligen oförändrade. I avhandlingen har jag inte heller gått närmare in på denna allmänna diskussion. Jag har däremot mer ingående undersökt frågan om hur man just under kriget har velat motivera dödsstraff. Rätt allmän är den i synnerhet tidigare förfäktade åsikten att dödsstraff kan accepteras i kristider, även i det fall att dess bibehållande under fredstid motsätts. Det har påpekats i litteraturen att till exempel krigstida brott, såsom spioneri, kan ha allvarligare konsekvenser för hela staten än något fredstida brott. De som kategoriskt motsätter sig dödsstraff utgår från att detta strider mot envars rätt till liv och att det är irrelevant om straffet döms ut under freds- eller krigstida förhållanden. Det principiella motståndet mot dödsstraff kan emellertid vara mindre under krig, när en våldsam död också i övrigt är en alldaglig företeelse.

De centrala frågorna i min doktorsavhandling är följande:

1. Att utreda hur många personer som under andra världskriget i Finland dömdes till döden, avrättades eller sköts med stöd av förmans rätt att bruka vapen. 
2. Att undersöka det iakttagna förfarandet särskilt med hänsyn till den åtalades (misstänktes, dömdes) rättsskydd genom

a) tolkningen av straffbestämmelser vid utdömande av dödsstraff,

b) andra faktorer som påverkade urvalet av avrättade och

c) myndighetsförfarandet vid utdömande av dödsstraff.

3. Att enligt brottstyp bedöma syftena med dödsstraffen och hur de uppnåddes.

Den krigstida rättsskipningen har inte undersökts i någon större omfattning tidigare. Mitt forskningsmaterial bestod huvudsakligen av tämligen välbevarade domstols- och andra myndighetshandlingar om dödsstraff och avrättningar. Handlingarna gav en pålitlig bild av antalet dödsdomar och avrättningar. Handlingarna i de mål som resulterade i dödsdomar är offentliga i dag. Vissa av dem blev offentliga först sedan jag i samband med avhandlingen ansökte om det. I mitt material ingick dessutom intervjuer jag gjorde med personer med egna erfarenheter av den krigstida rättsskipningen samt litteratur.

\section{Bakgrunden till de krigstida domarna}

Finland, som tidigare hade varit en del av det svenska riket, införlivades med Ryssland år 1809. Den ryska kejsaren utfärdade år 1826 ett påbud, enligt vilket dödsstraff hädanefter inte skulle verkställas i Finland annat än för de allvarligaste mot staten riktade brotten. Härmed upphörde verkställigheten av dödsstraff under fredstid. Tidpunkten är internationellt sett mycket tidig. Den sista fredstida avrättningen skedde redan före kejsarens påbud, år 1825.

År 1889 stiftades en ny strafflag i Finland. Dödsstraff föreskrevs för bara ett fåtal brott; i praktiken närmast landsförräderi under krig samt mord. I bägge fallen var straffet alternativt. Med stöd av strafflagen har visserligen dömts ut dödsstraff för mord under fredstid, men dessa mildrades i högre rättsinstanser eller senast genom benådning.

Finland blev självständigt i december 1917. Självständigheten följdes våren 1918 av ett inbördeskrig mellan " vita", dvs. regeringstrupper, och revolterande "röda". I uppgörelsen efter kriget grundades domstolar för statsförbrytelser, som dömde personer på den förlorande "röda" sidan till döden. På 1930-talet fanns det rätt omfattande planer på att utvidga tillämpningsområdet för dödsstraff och att börja verkställa dessa, men planerna mötte också ett stort motstånd och realiserades sist och slutligen aldrig.

År 1886 stiftades en strafflag för finska militären. Med stöd av lagen utdömdes några dödsdomar under inbördeskriget år 1918. Sedan Finland hade blivit självständigt gavs en ny lag, strafflagen för krigsmakten, år 1919. Den innehöll hot om dödsstraff för ett flertal brott.

Den krigstida lagändring som var viktigast med avseende på dödsstraffet härstammar från juli 1944. Då infördes dödsstraff som påföljd för fanflykt. Reformen skall ses mot bakgrunden av att Sovjetunionen hade inlett sin storof- 
fensiv i juni 1944. Vid tiden för lagändringen hade läget vid fronten visserligen redan förbättrats genom att de finska trupperna hade intagit hållbara försvarspositioner. Krigsläget ansågs det oaktat som så oroväckande att lagändringen knappt väckte någon diskussion i till exempel riksdagen, som godkände den enhälligt några enstaka inlägg till trots.

\section{Antalet domar och avrättningar}

I Finland dömdes sammanlagt 681 dödsstraff ut under åren 1939-1946. (Året 1946 har inkluderats i undersökningen, eftersom högsta domstolen då utdömde det sista dödsstraffet.) Av dödsstraffen dömdes 579 (85\%) ut i fältkrigsrätter och så gott som alla andra i övriga krigsdomstolar (ståndrätter och överkrigsdomstolen som besvärsinstans). De allmänna domstolarna avkunnade bara 16 dödsstraff.

Fältkrigsrätternas dödsdomar blev vanligen inte föremål för prövning i högre rättsinstans, eftersom fältkrigsrätterna under största delen av kriget var behöriga att besluta om omedelbar verkställighet av dödsstraffen utan skyldighet att underställa domarna en högre domstol. Domarna var inte heller överklagbara. Det var i själva verket bara 104 dödsdomar som mildrades i högre rättsinstanser. Också antalet benådningar var litet, eftersom nådeansökningar var möjliga bara i sådana fall där dödsstraffet inte hade förordnats att omedelbart verkställas. När det antal personer som benådats eller av någon annan anledning inte avrättats avräknas från antalet dömda, blir resultatet 528 avrättade. Antalet avrättade är sannolikt något högre, eftersom handlingarna i vissa fall saknade uppgifter om de sista skedena i den dömdes liv.

Största delen av dödsstraffen (637) hänför sig till fortsättningskriget och till tiden omedelbart därefter (1941-1944). Under det korta vinterkriget utdömdes bara 37 dödsstraff.

Den sista avrättningen i Finland verkställdes den 15 september 1944. Åren 1945 och 1946 dömde de allmänna domstolarna ytterligare ut några dödsstraff för brott mot liv, men de ledde inte längre till avrättningar. Vid efterkrigstida rättegångar i Finland dömdes ingen till döden för till exempel krigsförbrytelser.

Under tiden 1939-1946 var 482 (71\%) av de dödsdömda och 410 (78\%) av de avrättade sovjetmedborgare, som hade gjort sig skyldiga till spioneri eller motsvarande brott. Totalt dömdes 522 och avrättades 443 sovjetmedborgare. Av de dömda var 157 (23\%) finska medborgare, av de avrättade var andelen klart mindre, $85(16 \%)$. Av de avrättade finska medborgarna var 67 soldater, 15 civilpersoner och 3 hörde till den sovjetiska armén (de hade bibehållit sitt finska medborgarskap).

Antalet dödsdömda fanflyktingar var 76. Av dem avrättades över hälften, 46. Till dödsstraff ledde, förutom spioneri och fanflykt, lands- och krigsförräderi (44 domar), brott mot liv (42), brott begångna av krigsfångar (29) och lydnadsbrott (8). 


\section{Förfarandet}

För spioneri dömdes enligt strafflagen för krigsmakten den som hörde till en fiendestyrka och som i hemlighet eller under lögnaktig förevändning samlade eller försökte samla uppgifter i syfte att överlämna dem till fienden. Det var ofta svårt att bedöma när verksamheten hade skett "i hemlighet eller under lögnaktig förevändning". De av fienden utsända personerna var ofta nämligen klädda på ett sådant sätt att det var omöjligt att genast urskilja om de bar en tillbörlig militäruniform eller inte. När det gäller klädseln var domstolspraxis i själva verket oenhetlig. Dessutom var domstolarna tvungna att ta ställning till frågan när en person hade samlat eller försökt samla uppgifter. I vissa fall presumerades ett dylikt spionuppsåt föreligga trots tämligen obefintlig bevisning; då fäste domstolen avseende närmast vid personens klädsel.

En spion fick säkrast behålla livet om han utan dröjsmål frivilligt anmälde sig hos myndigheterna och sanningsenligt redogjorde för sitt uppdrag. Det kan anses som ett synnerligen strängt krav. Spionen kunde till och med helt undgå åtal, om han började arbeta för finländarna, i till exempel underrättelsetjänsten. I sådana fall gavs den militära ändamålsenligheten företräde framom kravet på likabehandling av mål inför domstol. Att gärningen var obetydlig kunde också medföra att spionen ådömdes ett lindrigare straff än dödsstraff.

Krigshändelserna påverkade i allmänhet inte domspraxis. Det är fråga om ett klart undantag när alla de 30 dödsdomar för fanflykt som hänsköts till överkrigsdomstolen på sommaren 1944 mildrades. Även benådningarna påverkades troligen i viss mån av krigsförloppet: år 1944 bifölls en relativt stor del av nådeansökningarna, och en majors nådeansökan var fortfarande, efter ett och ett halvt års väntan, oavgjord vid krigsslutet. I slutet av augusti 1944 avslogs å andra sidan nådeansökningarna av två rätt välkända finländare som hade gjort sig skyldiga till politiska brott, och de hann avrättas medan fortsättningskriget fortfarande pågick.

Dödsstraffen dömdes ut av oberoende domstolar, varför de åtalades rättsskydd i princip var gott. I Finland krävdes inte att krigsdomstolarnas domar skulle stadfästas av en militär förman för att träda i kraft (med undantag av dödsdomar som avkunnades av ståndrätterna).

I praktiken var den åtalades rättsskydd emellertid inte alls så fullständigt. Vissa av de förfaranden som äventyrade rättssäkerheten ansågs redan under kriget klandervärda; som exempel kan nämnas den påtryckning som militära förmän i viss utsträckning utövade på fältkrigsrätterna. Ingenting tyder likväl på att fältkrigsrätterna i regel skulle ha givit efter för påtryckningar. Av civilmyndigheterna var det främst statspolisen som försökte utöva ett visst inflytande på domstolarna, i allmänhet dock förgäves.

Rättsskyddet hotades också av inskränkningar i besvärsrätten samt begränsningar och hinder i möjligheten att anlita rättsbiträde. Under kriget ansåg man uppenbarligen att detta var helt normalt. Det var i synnerhet den avsaknade möj- 
ligheten att anföra besvär som hade betydelse i praktiken: nästan två tredjedelar av dödsstraffen grundade sig på domstolsavgöranden på underrättsnivå (fältkrigsrätter och ståndrätter).

I vissa fall förefaller den bevisning som utgjorde underlag för dödsdomen inte helt övertygande. Två lagstridiga avrättningar försämrar för sin del ytterligare den allmänna bilden av rättsskyddet. I det ena fallet dömdes en person under 18 år till döden och avrättades, vilket fortfarande i början av kriget stred mot lagen. Det andra fallet gällde en person som avrättades trots att hans nådeansökan var anhängig.

Ståndrätterna var inte oberoende i samma omfattning som fältkrigsrätterna, och ståndrättsprocessen var också i övrigt rätt problematisk med tanke på den åtalades rättsskydd. Det var emellertid bara en liten del (5\%) av dödsstraffen som dömdes ut av ståndrätterna.

\section{Syftet med dödsstraffen och hur det uppnåddes}

Under kriget var det otillåtet att diskutera dödsstraffen i massmedierna, och även riksdagen var mycket försiktig i sin behandling av frågan. Till exempel när riksdagen sommaren 1944 införde dödsstraff för fanflykt skedde det utan någon egentlig diskussion, helt enligt militärens önskemål. Det är klart att man under dessa omständigheter knappast alls dryftade de principiella frågorna om det verkliga syftet med dödsstraffet.

I spionmål ansågs dödsstraffet uppenbarligen som en självklar påföljd. I praktiken kunde detta inte ha någon stor preventiv verkan, eftersom spionerna vanligen bara lydde order när de utförde sina uppdrag. Hotet om dödsstraff kunde visserligen göra en spion mer benägen att samarbeta med dem som hade anhållit honom.

Motsättningen mellan det egna landets och fiendestatens krav gäller förutom spioner också befolkningen på ockuperade områden och krigsfångar. Med tanke på situationen för dessa människor ter sig dödsstraffet ofta som en oskäligt sträng påföljd.

Under de första decennierna av finsk självständighet bekämpades vänsterextremismen även med straffrättsliga medel. Dessutom avrättades personer som hade deltagit på den förlorande "röda" sidan i kriget år 1918. Diskussionen på 1930-talet visade att det i politiker- och juristkretsar fanns en beredskap att bruka dödsstraff gentemot politiska motståndare. Under kriget började man sedan döma ut sådana straff. Dödsstraff utdömdes visserligen i första hand för sabotage och spioneri eller medhjälp till dessa, varför man inte kan tala om någon egentlig politisk utrensning med hjälp av domstolarna. Personer som gjorde sig skyldiga till politiska brott lät sig inte alltid skrämmas av fängelsestraff, i synnerhet inte i det skedet av kriget, när de räknade med en snar frigivning som ett resultat av kriget. Inte heller detta är en god motivering för dödsstraff. Att avrätta människor för politiska brott kan nämligen förefalla särskilt oskäligt när kri- 
get är slut och nya politiska vindar blåser. En person som håller sig gömd för att undgå avrättning kan de facto efter några månader inneha en ministerpost, vilket hände i Finland.

Avrättningarna av fanflyktingar på sommaren 1944 var avsedda att ha en avskräckande effekt. Man sökte varnande exempel, som man effektivt informerade om vid fronten. Straffpraxis var inte oskäligt sträng i den bemärkelse att merparten av dödsstraffen ådömdes återfallsförbrytare. Det fanns ingen enhetlig straffpraxis, vilket inte heller riktigt kunde förväntas, eftersom det var fråga om statuerande exempel.

I praktiken kan man emellertid betvivla att avrättningarna av fanflyktingar hade några positiva effekter. Det förefaller som om avrättningarna i fråga ofta hade en skadlig inverkan på truppernas stridsmoral. Mot bakgrunden av att desertering i allmänhet inte torde ha varit ett särskilt överlagt brott, kunde den eftersträvade avskräckningseffekten av dödsstraff svårligen realiseras. Det förefaller som om den officiella normen med dödsstraffhot stred mot manskapets egna inofficiella disciplinnormer, varför inte heller straffhotets moral- eller sedvaneskapande inverkan kunde förverkligas. Dessutom ägde avrättningarna rum i ett mycket sent skede av kriget, vilket för sin del bidrog till att många ansåg dem så motbjudande. Det tiotal fall, där en fanflykting eller tredskande person sköts utan domstolsbehandling, synes ha väckt ännu större anstöt.

De stränga kriminaliseringarna i strafflagen för krigsmakten utsträckte sin verkan också till den allmänna strafflagen. Dödsstraff dömdes ut, förutom för politiska brott, även för brott mot liv. Ett antal mördare avrättades de facto. I februari 1944 riktade Sovjetunionen massiva bombningar mot Finland, speciellt Helsingfors. Efter bombningarna godkände riksdagen efter ringa diskussion en lagändring, som gjorde det möjligt att döma ut dödsstraff till och med för egendomsbrott, såvida dessa hade begåtts under luftangrepp eller motsvarande omständigheter. Sådana dödsstraff dömdes likväl aldrig ut i praktiken. Den exceptionella situationen hade ändå ökat lagstiftarens tilltro till stränga straff.

\section{Sammanfattning och slutsatser}

I sin helhet kan man konkludera att de fredstida rättsliga idealen rätt väl lyckades hävda sig i krigsdomstolarna och i den krigstida rättsskipningen över lag. Det fanns emellertid ett uppenbart tryck på att förfarandena skulle avspegla militära ideal samt vara stränga och militärt ändamålsenliga. De civila myndigheternas hantering av rättsliga och angränsande frågor påverkades också. Tidigare forskning har gett vid handen att den militaristiska förvaltningskulturen har en tendens att bli förhärskande i kristider, och detta bekräftas även i min undersökning. Hur riksdagen under världskriget diskuterade till exempel frågor som tangerade dödsstraffet visar ytterligare samma sak: riksdagen iakttog stor försiktighet och hade tillgång till bristfälliga uppgifter.

Eftersom krig inte varar för evigt, är det viktigt att domstolsverksamheten och 
rättsskipningen i allmänhet bygger på långsiktighet. Sådana förfaranden som snuddar vid laglighetens gränser försvårar återuppbyggnaden av samhället, som trots allt är en realitet när kriget eller krisen är över. Att låta krigsutgången avgöra om myndigheternas verksamhet under kriget skall undersökas eller inte, är i all sin cynism någonting otänkbart i dag. Åtminstone i den internationella straffrätten går man allt mera in för att samtliga parters krigstida agerande skall kunna undersökas oberoende av krigets utgång.

I min undersökning är det svårt att finna belägg för att dödsstraffet har några positiva effekter ens under krig. På kort sikt kan det ha en viss avskräckningseffekt på de egna medborgarna, men på längre sikt är verkningarna knappast gynnsamma. En fiendestats medborgare låter sig svårligen skrämmas av dödsstraff. Med avseende på brottets art förefaller de flesta krigstida dödsstraffen vara oskäliga påföljder, i synnerhet när saken bedöms efter kriget.

År 1949 antogs en lag genom vilken dödsstraffet avskaffades i Finland under fredstid. Lagen trädde i kraft i början av följande år. År 1972 avskaffades dödsstraffet helt ur påföljdssystemet. I dag finns det flera hinder för återinförande av dödsstraffet, såsom Finlands grundlag och internationella konventioner. Trots det är forskningsresultaten om verkningarna av dödsstraff inte bara historiskt betydelsefulla. De kan nämligen tillämpas på stränga straff över lag. I kristider är det lätt att kräva betydligt strängare straff, men när krisen väl är över kan det tänkas att man i själva verket får ångra de hårda domarna. I och med att samhället blir allt mer pluralistiskt är det sannolikt att medborgarna har diametralt olika åsikter om den politik som skall föras under en aktuell, allvarlig kris. Då vore det särskilt problematiskt att tillämpa stränga straffrättsliga medel på exempelvis regeringsmotståndare.

Också den som inte betraktar det absoluta skyddet av liv som ett hinder för dödsstraff kan svårligen förbise möjligheten till misstag. Detta är ett särskilt vägande hinder för dödsstraff. Det är speciellt i kristider som möjligheten till misstag kan öka.

Adress: Justitieministeriet

Lagberedningsavdelningen

Södra Esplanaden 10

PB 1

FIN - 00131 Helsingfors

Översatt från finska av Carl-Erik Skarp och Lenita Häggblom

Noter:

${ }^{1}$ Lindstedt, Jukka: Kuolemaan tuomitut. Kuolemanrangaistukset Suomessa toisen maailmansodan aikana. Helsinki 1999. $680 \mathrm{~s}$. 